\title{
IMPLICATIONS OF PATIENT CENTRING ON ORGAN DOSE IN COMPUTED TOMOGRAPHY
}

Bharti Kataria, Michael Sandborg and Jonas Nilsson Althen

\section{Linköping University Post Print}

\section{Tweet}

N.B.: When citing this work, cite the original article.

Original Publication:

Bharti Kataria, Michael Sandborg and Jonas Nilsson Althen, IMPLICATIONS OF PATIENT CENTRING ON ORGAN DOSE IN COMPUTED TOMOGRAPHY, 2016, Radiation Protection Dosimetry, 1-6.

http://dx.doi.org/10.1093/rpd/ncv527

Copyright: Oxford University Press (OUP): Policy B - Oxford Open Option A http://www.oxfordjournals.org/

Postprint available at: Linköping University Electronic Press

http://urn.kb.se/resolve?urn=urn:nbn:se:liu:diva-125340 
ID: OXMI2015-032

\section{Implications of patient centering on organ dose in}

\section{Computed Tomography}

Short running title: Patient centering affects doses in CT

Full postal address: Bharti Kataria,

Radiology Department,

Linköping University,

581 85, Linköping

Sweden

Affiliations: Bharti Kataria*1 ${ }^{*}$ Michael Sandborg ${ }^{2}$ and Jonas Nilsson Althén ${ }^{3}$

${ }^{1}$ Department of Radiology, Department of Medical \& Health Sciences, Center for Medical Image Science and Visualisation, Linköping University, County Council of Östergötland,Linköping, Sweden

${ }^{2}$ Department of Medical Physics, Department of Medical \& Health Sciences, Center for Medical Image Science \& Visualization, Linköping University, County Council of Östergötland, Linköping, Sweden

${ }^{3}$ Department of Medical Physics, Linköping University, County Council of Östergötland, Linköping, Sweden

*Corresponding author

E-mail: Bharti.Kataria@liu.se

Telephone: +46101042775 
ID: OXMI2015-032

\section{Implications of patient centering on organ dose in Computed Tomography}

Bharti Kataria, Michael Sandborg and Jonas Nilsson Althén

Automatic exposure control (AEC) in Computed Tomography (CT) facilitates optimization of dose absorbed by the patient. The use of AEC requires appropriate "patient centering" within the gantry, since positioning the patient off-center may affect both image quality and absorbed dose. The aim of this experimental study was to measure the variation in organ and abdominal surface dose during CT examinations of the head, neck/thorax and abdomen. The dose was compared at the isocenter with two off-center positions - ventral and dorsal to the isocenter. Measurements were made with anthropomorphic adult phantom and thermoluminescent dosemeters (TLDs). Organs and surfaces for ventral regions received lesser dose $(5.6 \%$ $39.0 \%$ ) than the isocenter when the phantom was positioned $+3 \mathrm{~cm}$ off-center. Similarly, organ and surface doses for dorsal regions were reduced by $5.0 \%-21.0 \%$ at $-5 \mathrm{~cm}$ off-center. Therefore correct vertical positioning of the patient at the gantry isocenter is important to maintain optimal imaging conditions. 
ID: OXMI2015-032

\section{INTRODUCTION}

Although the past two decades has seen an increase in the use of Computed Tomography (CT)

(1) the CT dose per examination has been reduced, partly due to the use of iterative image reconstruction. This technique minimizes image noise and can often lead to dose reduction without the loss of image information. Modern CT scanners offer multiple features in dose optimization, including angular (x- \& y-axis) and longitudinal z-axis tube current modulation (TCM). The TCM system adjusts the tube current to the specific shape, size and anatomy of the patient, to achieve the desired image quality with the help of localizer radiographs. The result is an appropriate balance between image noise and radiation exposure ${ }^{(2)}$. TCM, however, requires appropriate patient centering in the gantry. If the patient is off-center, both image quality and the absorbed dose are affected. Different types of bowtie or beam shaping filters can be selected, depending on the diameter and nature of the object being scanned. The purpose of these filters is to adjust the distribution of radiation emitted from the fan beam to the attenuation of the elliptical shape of the object. This is done by reducing the beam intensity at the peripheral sections of the fan beam. There are several studies showing that patient positioning errors in CT (Figure 1), affect both radiation dose and image noise. These studies ${ }^{(3 ; 4 ; 5 ; 6 ; 7)}$ show that off-center misalignment is a serious and common problem, particularly in the vertical direction. Therefore radiographers play an important role in planning and execution of a CT scan, especially when scanning thin and small patients.

The aim of this experimental study was to measure variation in organ and abdominal surface dose during CT examinations of the head, neck/thorax and abdomen regions. The doses were measured at the isocenter and two off-center positions in the vertical direction using thermoluminescent dosemeters (TLDs). Results were then compared to dose calculated at the isocenter using a software tool, CT Expo (Version 2.3.1) ${ }^{(8)}$. 
ID: OXMI2015-032

\section{MATERIAL AND METHODS}

An anthropomorphic male phantom, Model 701-D (CIRS, Norfolk, USA) ${ }^{(9)}$ was imaged and used to estimate the effect of vertical off-centering of the object in the gantry, on organ and surface dose.

TLDs were placed in locations corresponding to five radiation sensitive organs. The points were marked by their hole numbers in the phantom slices: 2 TLDs for the eyes $(14,15), 2$ for the thyroid gland $(30,31), 2$ for the breast $(93,94), 4$ for the kidneys $(186,187,188,189)$ and 2 for the testes $(268,269)$. Four TLD tablets were placed at each location and a mean value was calculated. To measure the circumference surface dose, seven dosemeters (each containing 4 TLD tablets) were taped onto the torso of the phantom at mid-axillary, mid-clavicular, center and mid-scapular positions. A Rados RE2000 TLD reader (Rados technology, Finland) and an Alnor Dosacus TLD irradiator were used to calibrate the individual TLD tablets. The TLDs were calibrated to measure personal dose equivalent $\mathrm{H}_{\mathrm{p}}(10)$ using the radiation quality N100 $(100 \mathrm{kV})$ and were traceable to secondary standard laboratory at National Radiation Safety Authority in Stockholm, Sweden. Some tablets were damaged and hence their readings were not used in the calculation of the mean organ doses. The estimated total uncertainty in the $\mathrm{H}_{\mathrm{p}}(10)$ in the calibration for radiation quality N-100 was $\pm 20 \%$ (95\% confidence level).

The reference vertical position (0-level) was set according to a typical vertical positioning procedure, with visual evaluation in the gantry followed by adjustment using the lateral localizer radiograph. CT scans were then performed using the lateral localizer for the head, both lateral and anterior-posterior (AP) localizing radiographs for the neck/thorax and abdomen, and clinical protocols (Table 1). The scanner was a Somatom Definition AS CTscanner (Siemens, Erlangen, Germany). 
ID: OXMI2015-032

Each region-of-interest was scanned 10 times, to obtain a sufficient measureable reading from the TLDs, and also to even out variation in individual TLD readings due to the variation in $\mathrm{x}$ ray tube start-position. This procedure was repeated for the two vertical off-center positions: $+3 \mathrm{~cm}$ ventral and $-5 \mathrm{~cm}$ dorsal of the 0 -level (isocenter).

Additional measurements were performed with a CT Dose profiler electronic dosemeter (RTI Electronics AB, Mölndal, Sweden). The profiler was taped to the torso of the phantom at the level of the diaphragm, centered in the horizontal direction. Scans were performed 10 times, using the same exposure parameters as for the abdominal series. They were performed over the thorax and abdomen region in order to study the variation in surface dose due to the random selection of the $\mathrm{x}-\mathrm{y}$ starting position of the $\mathrm{x}$-ray tube and vertical displacement.

The measured organ dose at the isocenter was compared with that calculated by the CT Expo software tool (version 2.3.1) ${ }^{(8)}$. Computed Tomography Dose Index $\left(\mathrm{CTDI}_{\mathrm{vol}}\right)$ and Dose Length Product (DLP) values were read from the dose reports. To obtain CT Expo values for the breast, the setting was switched to female phantom.

\section{RESULTS}

The variation in $\mathrm{CTDI}_{\mathrm{vol}}$ and DLP values with the phantom centered at the isocenter and the values corresponding to the two off-center positions are presented in Table 2 . The average measured and calculated organ doses at isocenter are presented in Table 3. For all regions, the CT Expo calculated values for the $\mathrm{CTDI}_{\mathrm{vol}}$ and DLP for the head were similar to corresponding values from the dose reports (Table 3). For the neck/thorax and abdomen, however, the calculated DLP was $7.4 \%$ and $15.0 \%$ higher, respectively, compared to the dose report value. The absorbed organ doses show a similar trend. An exception was the eye lens, where the CT-Expo value of 60.6 mGy was higher than the measured mean value of 54.4 mGy. CT Expo values were lower however, for the breast (2.7 mGy vs $4.0 \mathrm{mGy})$ and thyroid 
ID: OXMI2015-032

(4.5 mGy vs $6.1 \mathrm{mGy}$ ) doses. The kidneys also had a lower calculated value (8.0 mGy) compared to a measured value of $10.0 \mathrm{mGy}$.

The relative absorbed organ dose deviations are presented in Figure 2, i.e. as a percentage of the difference from reference level 0 . When off-centered by $3 \mathrm{~cm}$ above isocenter, the ventrally located organs e.g. eyes, thyroid and testes, received less dose compared to values at isocenter. The relative deviation range for the eyes was $-38.5 \%$ to $-39.0 \%$, thyroid $-5.6 \%$ to $-11.0 \%$ and testes $-32.3 \%$ to $-35.7 \%$. Even ventral surface doses were much lower than the values obtained at isocenter, $-19.9 \%$ to $-36.7 \%$.

Similarly, the dorsally located organs e.g. kidneys, $-12.8 \%$ to $-21.0 \%$, and dorsal surface dose values, $-13 \%$ to $-16 \%$, were lower compared to reference level (0) values at $-5 \mathrm{~cm}$ offcenter. Ventral organs such as the breasts and eyes received a higher dose compared to isocenter, with values ranging 5.4\% $-6.7 \%$ and 5.2\% $-12.0 \%$, respectively. At $-5 \mathrm{~cm}$ offcenter, the ventral surface doses were lower, $-0.1 \%$ to $-19.0 \%$, and for the testes, $-5.0 \%$ to $-7.5 \%$.

Some variations in absorbed dose were found between the right and left sides of the phantom (see Figure 2). The results from the individual surface dose measurement with the CT dose profiler indicated that the relative standard deviation (SD) in the ventral surface dose is $8-12 \%$ between individual scans. The surface dose values are presented in Figure 3. The relative increase in absorbed surface dose as determined with the CT dose profiler was $+43 \%$, with the phantom positioned $-5 \mathrm{~cm}$ below isocenter. The relative dose reduction was $-16 \%$ at $+3 \mathrm{~cm}$ above the isocenter. 
ID: OXMI2015-032

\section{DISCUSSION}

With proper patient alignment or centering, with respect to the bowtie filter, the peripheral, thinner sections of the phantom receive lesser dose thereby maintaining a uniform photon flux to the detectors. The results of this study show that there is a difference in absorbed dose between scanning the phantom centered correctly at the isocenter and scanning the phantom positioned off-center in either vertical directions in the gantry. When the phantom was positioned off-center, the points located at organ positions received more or less dose depending on the attenuation due to the bowtie filter. Similar results were obtained by Kaasalainen et al ${ }^{(7)}$ and Habibzadeh et al ${ }^{(5)}$. These studies showed that when the scanning object was aligned off-center, below the isocenter, there was an increase in dose at the upper surface and an increase in image noise at the lower half of the phantom.

The present study showed that the absorbed doses to the organs and peripheral, thinner regions of the phantom were significantly lower when off-centered and positioned in the field of the high-attenuation section of the bowtie filter. When the phantom is positioned below the isocenter, the ventral surface is further away from the radiation source. Therefore it is possible that the inverse square law effect contributes to the dose reduction when the $\mathrm{x}$-ray tube is in the AP position. Lower absorbed dose values were also seen for points at the ventral surface and the testes organ points at $-5 \mathrm{~cm}$. These could be explained by misoperation of the TCM. The apparent object size may be misinterpreted on the localizer radiograph as the system assumes the object is at the isocenter, and implementation of the TCM would be adjusted accordingly ${ }^{(10)}$. With the object centered below the isocenter, the object's size is estimated to be smaller than the actual size. The TCM therefore predicts a lower $\mathrm{CTDI}_{\mathrm{vol}}$ (Table 2). One would expect that the absorbed dose for points at the kidneys would be higher at $+3 \mathrm{~cm}$, however it was slightly lower. Even though the kidneys are dorsal, they are not peripheral organs. Since the anatomical position was not far enough from the center in the vertical 
ID: OXMI2015-032

direction, they did not render a higher organ dose, even though the CTDI $\mathrm{vol}_{\mathrm{vo}}$ and DLP were slightly higher for this position.

Toth et al. ${ }^{(6)}$ describe clinical situations of patient off-centering, stating that the positioning of adult patients off-center was more prevalent in the vertical direction compared to the horizontal direction. Since patients are generally scanned in the supine position, the tendency for vertical misalignment shows a larger distribution below the isocenter and the off-centering is more extent for thin patients ${ }^{(5 ; 6)}$. The consequence of this misalignment is that there is an increase in absorbed dose to the dose-sensitive anterior organs, such as breasts, as shown in the study presented in this report.

Although the measured dose was averaged over $10 \mathrm{CT}$ scans for each region-of-interest, there were slight differences in measured dose for the right and left sides of both the paired organs and the peripheral surface dose measurements. This bias could depend on the start position of the X-ray tube and was confirmed by the results of the CT dose profiler measurements for all three vertical positions. For the CT dose profiler, the relative difference in ventral surface dose to the isocenter also increased when the phantom was positioned below the isocenter and decreased when positioned above the isocenter. The former result contradicted the TLD measurements. It is possible that CT dose profiler is more accurate than the TLD dosemeters. Start position of the tube has bearing on dose as different tube start position angles create a phase shift in the peripheral dose profile. This results in dose variation along the z-axis. Since the tube start-position could not be controlled, it was not possible to perform multiple scans using the exact same start angle ${ }^{(11)}$. A significant reduction in organ dose could be achieved if the option to choose the start angle were provided ${ }^{(12)}$.

Measurements were performed at only two off-center positions. The off-center positioning of the phantom above the isocenter was limited to $3 \mathrm{~cm}$, due to the limits of the table elevation in 
ID: OXMI2015-032

this direction. The entire phantom was loaded with dosemeters, and all regions-of-interest were scanned consecutively. Therefore there may have been an increase in the absorbed dose due to scatter in overlapping regions of the anatomy. Ideally, the different regions-of-interest should have been scanned separately. However, in clinical practice, overlapping scans are normally performed for neck, thorax and abdomen, therefore this approach gives a more realistic result.

For the head examination, the gantry tilt was limited to $10^{\circ}$ when the phantom was off-center below the isocenter. For the other two positions, a gantry tilt of $14^{\circ}$ was used. This difference in tilt may have affected the accuracy of the absorbed dose measurements for the eyes, since the scan length and area of irradiation are affected by the tilt angle.

When comparing the measured dose with the CT-Expo calculations (Table 3), the eye lens dose was somewhat higher in the simulation calculations. This could be because in the experimental study, the head scan was performed with a tilted gantry to minimize the radiation dose to the eye lens, as done in clinical practice. This is impossible to simulate in CT-Expo, where dose estimates are made for the whole head with the scan axis parallel to the long axis of the phantom. Overall, the CT-Expo calculations were in close agreement to the measured values. The exact scan length, however, could not be accurately simulated, so an approximation was used. The latest version of CT-Expo incorporates over-ranging in the calculations, which could improve the agreement with measured dose values ${ }^{(13)}$. The higher DLP values for the neck/thorax and abdomen, compared to the measured values, could be due to discrepancies in the scan length. This is because it is difficult to select the exact scan length in the mathematical phantom used in CT Expo. The calculated dose values to the breasts were slightly lower than the measured values. This could be due to the overlapping volume of thorax and abdomen scans, which would increase the dose to the measured points. 
ID: OXMI2015-032

The effect of off-center positioning on image noise was not investigated in this study, nor the importance of using a lateral localizer radiograph.

\section{CONCLUSION}

Patient misalignment in the vertical direction affects the dose to organs in the head, neck/thorax and abdomen during CT examinations. Points in ventral organs and surfaces received lesser dose $(5.6 \%-39.0 \%)$ than those at the isocenter, when positioned off-center by $+3 \mathrm{~cm}$. Lower dose increases image noise which affects image quality. Similarly, dose to the dorsal organs and surface points were reduced by $5.0 \%-21 \%$, when positioned $-5 \mathrm{~cm}$ offcenter. Correct vertical positioning at the gantry isocenter is important to maintain optimal patient dose.

\section{ACKNOWLEDGEMENTS}

This work has been conducted within the Centre for Medical Image Science and Visualization (CMIV) at Linköping University, Sweden. CMIV is acknowledged for access to a leading edge research infrastructure. 


\section{References}

1. Kalra, M.K. and Toth, T.L. Part 1:Radiation risks in multidetector CT. Patient centering in MDCT: Dose effects. In:(Eds.)Gevenois, P.A. and Tack, D. Radiation dose from adult and pediatric multidetector computed tomography. Springer-Verlag (2007) ISBN 978-3-54028888-6.

2. Toth, T.L. Image quality in CT: Challenges and perspectives. In: (Eds.) Tack. D. Kalra, M. and Gevenois, P.A. Radiation dose in Multidetector CT. Springer Verlag (2012) ISBN 978-3642-24534-3.

3. Matsubara, K., Koshid, K., Ichikawa, K., Suzuki, M., Takata, T., Yamamoto, T. and Matsui, O. Misoperation of CT automatic tube current modulation systems with inappropriate patient centering: phantom studies. AJR. 192, 862-865 (2009).

4. Gudjonsdottir, J., Svensson, J.R., Campling, S., Brennan, P.C. and Jonsdottir, B. Efficient use of automatic exposure control systems in computed tomography requires correct paitent postioning. Acta Radiol. 50, 1035-1041 (2009).

5. Habibzadeh, M.A., Ay, M.R., Kamali Asl, A.R., Ghadiri, H., and Zaidi, H. Impact of miscentering on patient dose and image noise in x-ray CT imaging: Phantom and clinical studies. Phys. Med. 28, 191-199, (2012).

6. Toth, T., Ge, Z. and Daly, M.P. The influence of patient centering on CT dose and image noise. Med. Phys. 34, 3093-3101 (2007).

7. Kaasalainen, T., Palmu, K., Lampinen, A. and Kortesniemi, M. Effect of vertical positioning on organ dose, image noise and contrast in pediatric chest CT - phantom study. Pediatr. Radiol. 43, 673-684(2013).

8. Stamm, G., Nagel, H.D. Users Guide CT Expo V 2.1. Impressum, (2012).

9. CIRS Tissue Simulation \& Tissue Technology. Atom dosimetry verification phantoms. [Online] 2015. Available on http://www.cirsinc.com/products/modality/33/atom-dosimetryverification-phantoms/ (10th August, 2014 date last accessed).

10. Lambert, L.W., Kumar, S., Chen, J.S., Wang, J.Z., Gould, R.G., and Yeh, B.M. Investigating the $\mathrm{CT}$ localizer radiograph; acquisition parameters, patient centering and their combine influence on radiation dose. Br.J.Radiol. 88 (2015).

11. Zhang, D., Savandi, A.S., Demarco, J.J., Cagnon, C.H., Angel, E., Turner, A.C., Cody, D.D., Stevens, D.M., Primak, A.N., McCollough, C.H., et al. Variability of surface and center position radiation dose in MDCT: Monte Carlo simulations using CTDI and anthropomorphic phantoms. Med. Phys. 36, 1025-1038 (2009).

12. Zhang, D., Zankl, M., DeMarco, J.J., Cagnon, C.H., Angel, E., Turner, A.C. and McNittGray, M.F. Reducing radiation dose to selected organs by selecting the tube start angle in MDCT helical scans: A Monte Carlo based study. Med. Phys.36, 5654-5664 (2009). 
ID: OXMI2015-032

13. Brady, Z., Cain, T.M. and Johnston, P.M. Comparison of organ dosimetry methods and effective dose calucation methods for paediatric CT. Australas Phys Eng Sci Med. 35, $117-$ 134 (2012). 
ID: OXMI2015-032

Table 1. Acquisition parameters for CT scan of the head, neck/thorax and abdomen using a

128-slice Siemens Somatom Definition AS Scanner with lateral (head) and both AP and lateral (neck/thorax, abdomen) localizer radiographs.

\begin{tabular}{|c|c|c|c|c|c|c|c|c|c|}
\hline $\begin{array}{c}\text { Series } \\
\text { Description }\end{array}$ & $\begin{array}{c}\text { Voltage } \\
(\mathrm{kV})\end{array}$ & $\begin{array}{l}\text { Quality } \\
\text { ref. } \\
\text { Tube } \\
\text { Current } \\
\text { Time } \\
\text { Product } \\
\text { (mAs) }\end{array}$ & $\begin{array}{c}\begin{array}{c}\text { Acquisition } \\
\text { mode }\end{array} \\
\end{array}$ & $\begin{array}{c}\text { Dose } \\
\text { Modulation }\end{array}$ & $\begin{array}{c}\text { Care } \\
\text { Dose } \\
\text { 4D }\end{array}$ & $\begin{array}{c}\text { Rotation } \\
\text { time }\end{array}$ & Pitch & $\begin{array}{c}\text { Collimation } \\
(\mathbf{m m})\end{array}$ & $\begin{array}{c}\text { Slice } \\
\text { Thickness } \\
(\mathbf{m m})\end{array}$ \\
\hline Head & 120 & 350 & Helical & on & on & 0.5 & 0.55 & 0.6 & 1 \\
\hline Neck/Thorax & 100 & 65 & Helical & on & on & 0.5 & 1.2 & 0.6 & 5 \\
\hline Abdomen & 120 & 140 & Helical & on & on & 0.5 & 0.6 & 0.6 & 5 \\
\hline
\end{tabular}

Scanned regions: Head (skull base to top of head), Neck/Thorax (C2-L1), Abdomen (Th12- phantom end) 
ID: OXMI2015-032

Table 2 CTDI $_{\mathrm{vol}}$ and DLP values for head, neck/thorax and abdomen at the isocenter and two off-center positions, $+3 \mathrm{~cm}$ ventral and $-5 \mathrm{~cm}$ dorsal of the isocenter.

\begin{tabular}{|c|c|c|c|}
\hline Body Region & Position & $\begin{array}{c}\text { CTDIvol } \\
\text { (mGy) }\end{array}$ & $\begin{array}{c}\text { DLP } \\
\left(\mathrm{mGy}^{\circ} \mathrm{cm}\right)\end{array}$ \\
\hline \multicolumn{4}{|l|}{ Head } \\
\hline & $3 \mathrm{~cm}$ ventral & 57.57 & 939.3 \\
\hline & isocenter & 61.19 & 928.0 \\
\hline & $5 \mathrm{~cm}$ dorsal & 65.84 & 1031.5 \\
\hline \multicolumn{4}{|l|}{ Neck/Thorax } \\
\hline & $3 \mathrm{~cm}$ ventral & 2.02 & 86.5 \\
\hline & isocenter & 1.85 & 81.5 \\
\hline & $5 \mathrm{~cm}$ dorsal & 1.82 & 81.8 \\
\hline \multicolumn{4}{|l|}{ Abdomen } \\
\hline & $3 \mathrm{~cm}$ ventral & 6.24 & 343.8 \\
\hline & isocenter & 6.33 & 337.5 \\
\hline & $5 \mathrm{~cm}$ dorsal & 6.07 & 328.3 \\
\hline
\end{tabular}


Table 3. Comparison of dose to points in various organs of the head, neck/thorax and abdomen. Doses were calculated using CT Expo (v.2.3.1). Measurements were based on TLD responses in an anthropomorphic adult male phantom (Atom). The phantom was positioned at the isocenter in a 128 slice Siemens Somatom Definition AS scanner.

\begin{tabular}{|c|c|c|c|c|c|c|c|}
\hline \multirow[b]{2}{*}{$\begin{array}{l}\text { Body } \\
\text { Region }\end{array}$} & \multirow[b]{2}{*}{ Organ } & \multicolumn{3}{|c|}{ CT EXPO Calculations } & \multicolumn{3}{|c|}{ Phantom Measurements } \\
\hline & & $\begin{array}{c}\text { Organ } \\
\text { dose } \\
(\mathrm{mSv})\end{array}$ & $\begin{array}{c}\text { CTDI }_{\text {vol }} \\
\text { (mGy) }\end{array}$ & $\begin{array}{c}\text { DLP } \\
\left(\mathrm{mGy}^{*} \mathrm{~cm}\right)\end{array}$ & $\begin{array}{c}\text { Organ } \\
\text { dose } \\
(\mathrm{mSv})\end{array}$ & $\begin{array}{c}\text { CTDI }_{\text {vol }} \\
\text { (mGy) }\end{array}$ & $\begin{array}{c}\text { DLP } \\
\left(\mathrm{mGy}^{*} \mathrm{~cm}\right)\end{array}$ \\
\hline Head & Eyes & 60.6 & 61.0 & 928 & 54.4 & 61.19 & 928 \\
\hline $\begin{array}{l}\text { Neck/ } \\
\text { Thorax }\end{array}$ & $\begin{array}{l}\text { Thyroid } \\
\text { Breasts }\end{array}$ & $\begin{array}{l}4.5 \\
2.7\end{array}$ & 1.8 & 87 & $\begin{array}{l}6.1 \\
4.0\end{array}$ & 1.85 & 81.5 \\
\hline Abdomen & $\begin{array}{l}\text { Kidneys } \\
\text { Testes }\end{array}$ & $\begin{array}{r}8.0 \\
10.6\end{array}$ & 6.3 & 392 & $\begin{array}{l}10.0 \\
10.8\end{array}$ & 6.33 & 337.5 \\
\hline Surface & $\begin{array}{l}\text { Ventral } \\
\text { Dorsal }\end{array}$ & - & - & - & $\begin{array}{r}(\mathrm{ma} / \mathrm{DX}) 11.13 \\
(\mathrm{mc} / \mathrm{DX}) 12.93 \\
\\
\quad(\mathrm{~ms} / \mathrm{DX}) 9.4\end{array}$ & (c)11.08 & $\begin{array}{l}(\mathrm{ma} / \mathrm{DX}) 10.70 \\
(\mathrm{mc} / \mathrm{DX}) 13.10 \\
\mathrm{~ns} / \mathrm{SIN}) 9.85\end{array}$ \\
\hline $\begin{array}{l}\mathrm{DX}=\text { Dexter } \\
\text { The experim } \\
\text { measuremer }\end{array}$ & $\begin{array}{l}\text { SIN = Sini } \\
\text { ental measu } \\
\text { ts. In CT Ex }\end{array}$ & $\begin{array}{l}\text { ter, } m a=n \\
\text { ements fo } \\
\text { o the bre }\end{array}$ & $\begin{array}{l}\text { id-axillary } \\
\text { paired org }\end{array}$ & $\begin{array}{l}\mathrm{mc}=\text { mid-cla } \\
\mathrm{ns} \text { are shown }\end{array}$ & $\begin{array}{l}\text { icular, } \mathrm{c}=\text { center } \\
\text { s mean values o } \\
\text { ed by switching }\end{array}$ & $\begin{array}{l}\mathrm{r}, \mathrm{ms}=\mathrm{mid} \\
\text { f either } 2 \mathrm{c} \\
\text { to a femal }\end{array}$ & $\begin{array}{l}\text {-scapular } \\
\text { or } 4 \\
\text { e phantom }\end{array}$ \\
\hline
\end{tabular}


ID: OXMI2015-032

Figure 1 Effect of the bowtie filter on beam intensity and dose at the isocenter and two offcenter positions above and below the isocenter.

Figure 2. Relative organ dose deviations for both off-center positions in the vertical direction. Percentages are relative to dose values obtained at the reference isocenter ("Level-0") for head, neck/thorax and abdominal CT scans using a 128-slice Siemens Somatom Definition AS scanner. DX = Dexter, $\mathrm{SIN}=$ Sinister

22(V) ventral surface dose (anatomical positions): $(\mathrm{ma})=$ mid-axillary, $(\mathrm{c})=$ center,$(\mathrm{mc})=$ mid-clavicular

22(D) dorsal surface dose (anatomical positions): (ms) = mid-scapular

Figure 3 CT Dose Profiler ventral surface dose measurements (mGy) $\pm(\mathrm{SD})$, with relative dose value $(\%)$ from that of the isocenter, for both off-center positions $+3 \mathrm{~cm}$ ventral and $-5 \mathrm{~cm}$ dorsal. 


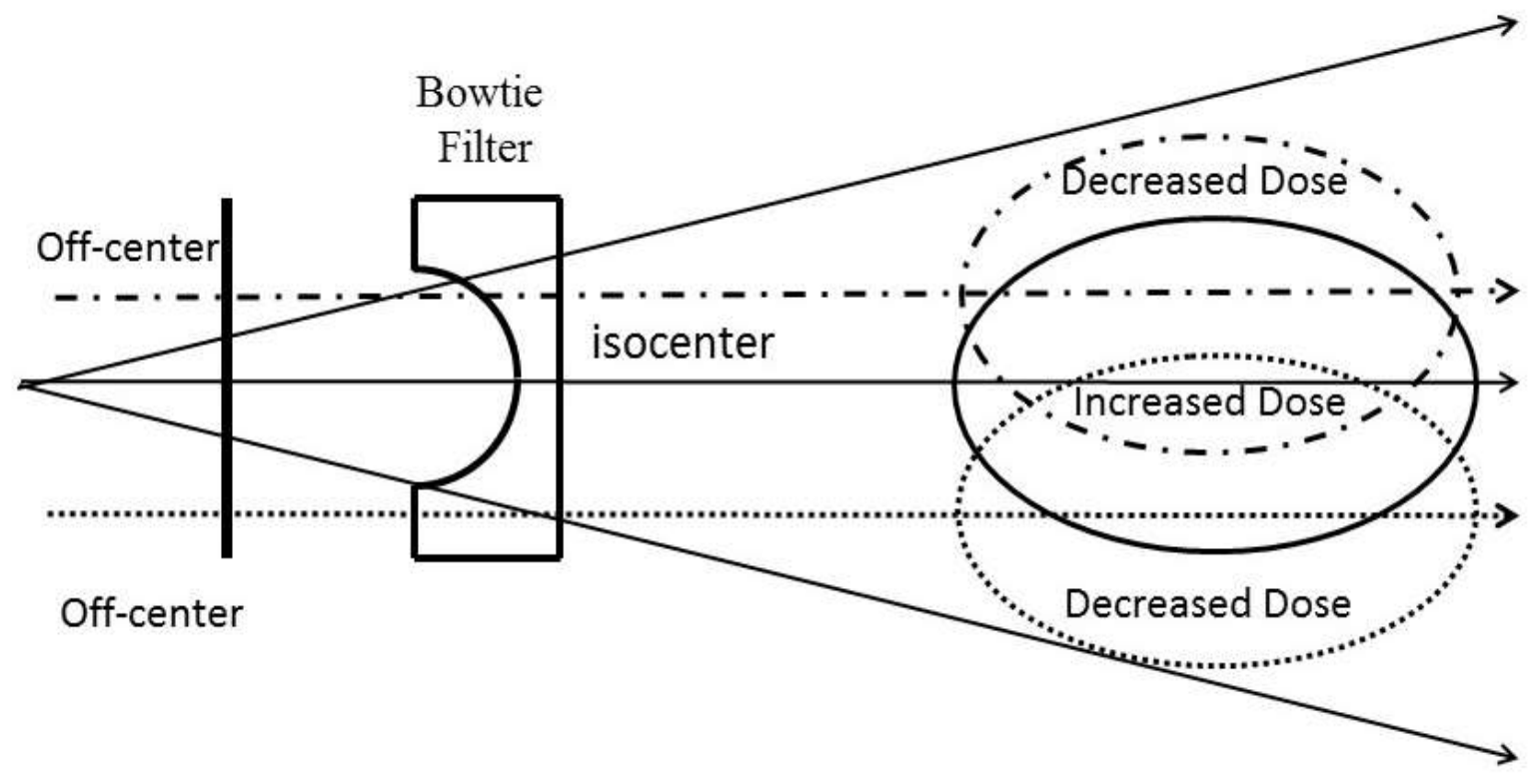


ID: OXMI2015-032

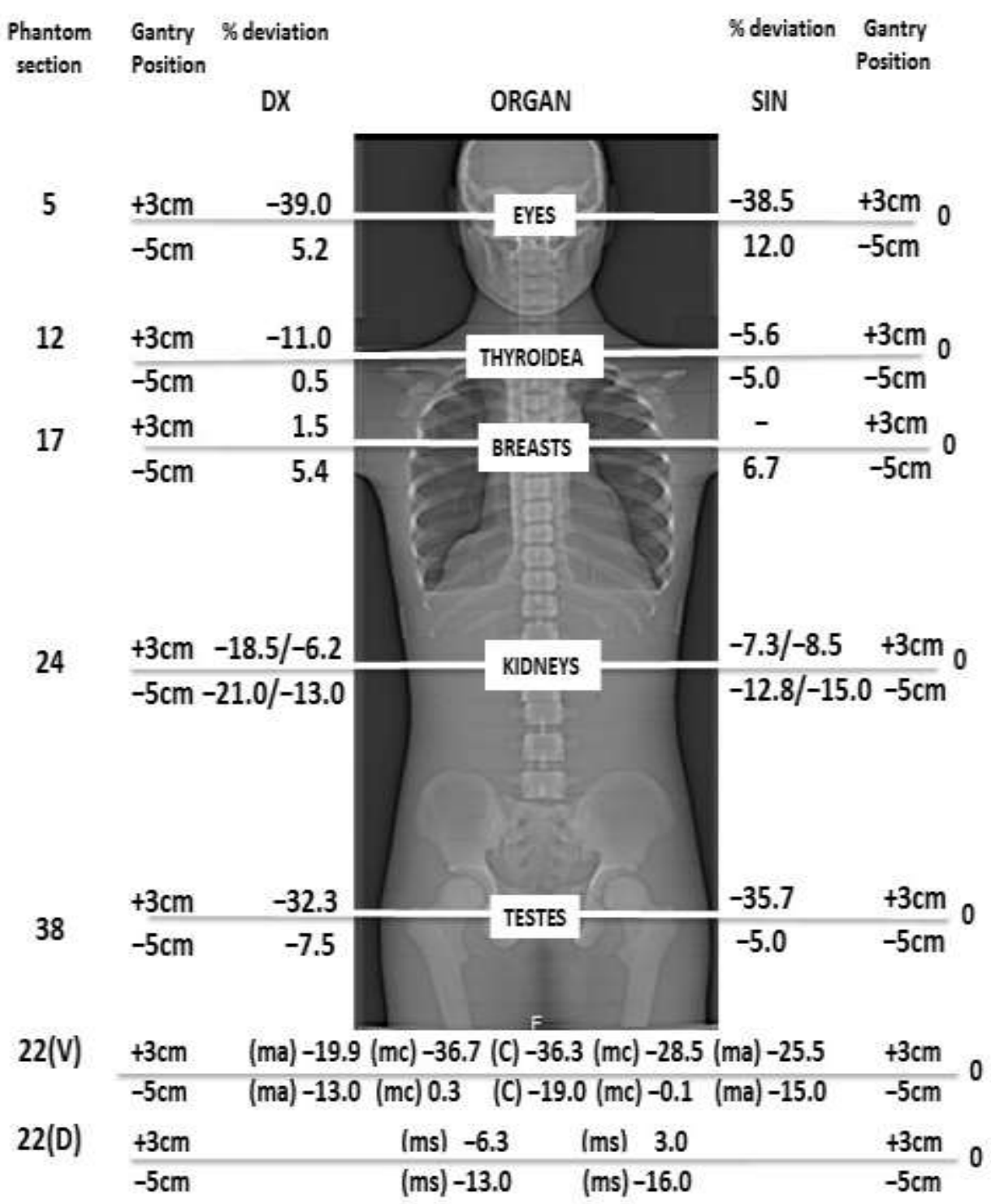


ID: OXMI2015-032

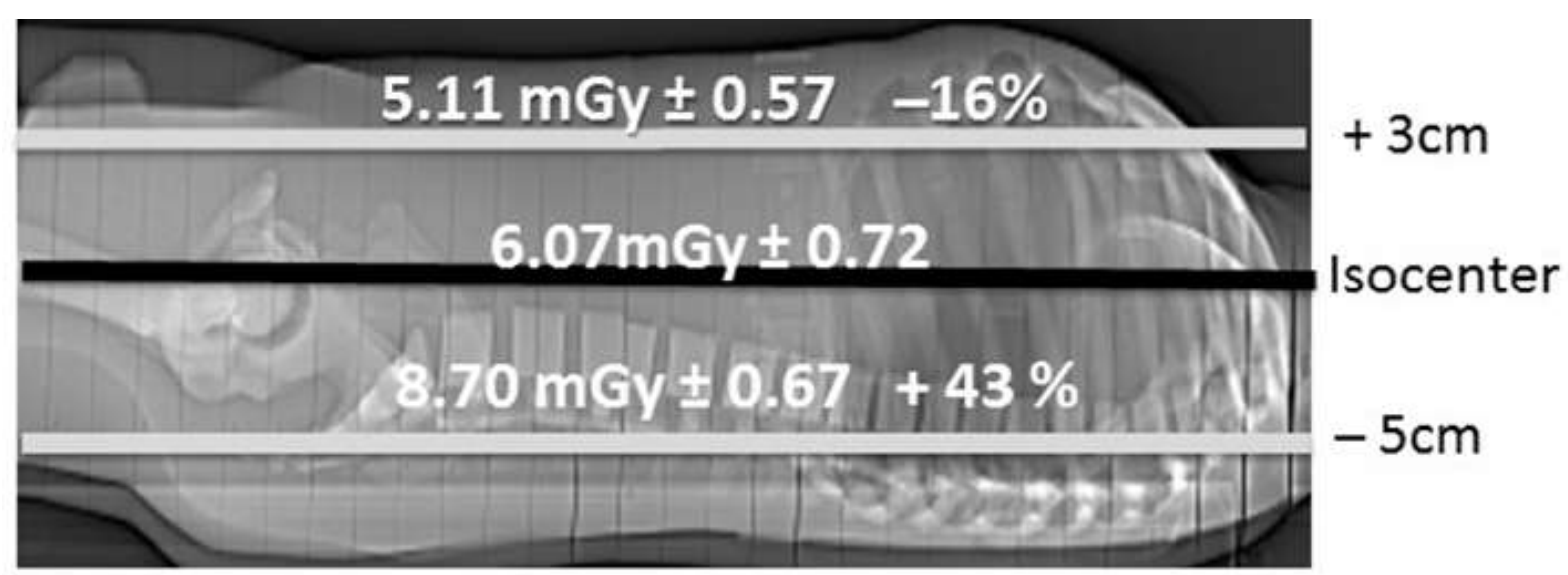

